\title{
Undergraduate research in primary care: is it sustainable?
}

Melvyn Jones, Surinder Singh and Richard Meakin Department of Primary Care \& Populations Sciences, Royal Free \& University College Medical Schools, University College London, Archway Campus, London, UK

\begin{abstract}
Aim: To describe the research project component of the BSc in Primary Health Care and to discuss the issues faced by students and faculty in attempting to complete a student-led research project. Background: Medical schools increasingly expect medical students to undertake research as part of intercalated BSc's or in self-selected study modules. This research has historically been laboratory based, 'piggybacking' onto existing projects. Projects initiated by students themselves and studies in primary care or community settings are more unusual. Methods: A qualitative study, based on interviews with students and examiners, triangulated with data from the peer review process and personal observations on the running of the course. Setting: A London medical school, running an intercalated BSc in Primary Health Care. Findings: We interviewed 24 of 26 students and two external examiners during the interview period of the study. Students successfully undertook research, from initial question through to publication. Overall, 90 dissertations were completed since 1997, of which half used a qualitative methodology (45/90). Ten projects have subsequently been published; there were also 16 conference presentations and 6 research letters. Themes from the interview data include: the students' strong sense of project ownership, the difficulties of being a novice researcher, the difficulties posed by the research governance hurdles, the beneficial and for some students adverse impact (stress and coping with unsuccessful projects) and finally, the impact on their careers. Conclusion: Students gain considerably from this learning process, not only by undertaking their own research, but they also gain in terms of acquisition of transferable skills such as critical appraisal and improved self-directedness. Project completion and publication rates suggest that programmes developing undergraduate initiated research projects can be as successful as those for other novice researchers. The student-led project is a fragile endeavour, but currently is sustainable.
\end{abstract}

Key words: education; ethics; medical; research; students

Received: March 2007; accepted: September 2007

\section{Introduction}

Research undertaken by medical undergraduates has been reported both in the UK (McManus et al., 1999) and internationally (Kemph et al.,

\footnotetext{
Address for correspondence: Melvyn Jones, Department of Primary Care \& Populations Sciences, Royal Free \& University College Medical Schools, University College London, Archway Campus, London N19 5LF, UK. Email: m.jones@pcps.ucl.ac.uk
}

(C) 2008 Cambridge University Press
1991; Jacobs and Cross, 1995; Gonzales et al., 1998; Jones and Hsu-Hage, 1999; Frishman, 2001; Joubert, 2006). In some European countries such as Germany, medical student research is mandatory (Cursiefen et al., 1995). In the UK, while understanding the scientific method is a core component of undergraduate training, the learning of research methods is not (General Medical Council, 2002). However, medical schools in the UK are increasingly expecting their undergraduates to undertake research projects, either as part of an intercalated 
BSc or as part of student selected components (General Medical Council, 2002).

There is some evidence that involvement of doctors in research both improves clinical care for patients (Mant, 1997) and improves their critical appraisal skills (Hebert et al., 2003). This would suggest that developing research skills among medical undergraduates may be an important goal for undergraduate medical education. There is evidence that undertaking research as an undergraduate may have broad benefits for undergraduates, influence career choices and increase medical research capacity (Morrison, 2004).

Surveys show that those students who have done research projects were: positive about the learning experience (Stefani et al., 1997; Heylings and Tariq, 2001), able to formulate research questions, analyse data and review the literature critically (Jacobs and Cross, 1995; Frishman, 2001; Greenhalgh and Wong, 2003), suggesting this process helps them to practice evidence-based medicine. These students are also more likely to present at research meetings and submit papers for publication (Smith, 1986; Jacobs and Cross, 1995; Zier and Stagnaro-Green, 2001). These students were also more likely to do further research (Eaton and Thong, 1985; Kemph et al., 1991).

Those students with undergraduate research training (Segal et al., 1990) or intercalated degrees (Wyllie and Currie, 1986) were more likely to pursue academic careers (McManus et al., 1999; Lambert et al., 2001), but this may be a characteristic of these individuals rather than the courses, as those who are more interested in research are more likely to complete intercalated BSc's (McManus et al., 1999; Lambert et al., 2001). These students are also more likely to teach (Kemph et al., 1991). Students with undergraduate research training and intercalated degrees are also less likely to become general practitioners (GPs; McManus et al., 1999; Lambert et al., 2001). However, the research that is undertaken by undergraduates, tends largely to be based in the laboratory (Jacobs and Cross, 1995), although some projects are undertaken in the community (Epstein et al., 1983; Reuben and Smith, 1987; Joffe and Farrant, 1989; Griswold et al., 1991; Shapiro et al., 1994; Jones and HsuHage, 1999; Murdoch-Eaton and Jolly, 2000).

In recent years, the addition of the administrative burdens of research governance to the need to obtain Ethics Committee approval has resulted in problems for student researchers, in particular due to the time constraints posed by the course timetable. Some groups (Jones and Hsu-Hage, 1999; Oakeshott and Yadava, 2006) have questioned whether students can now reasonably be expected to navigate their projects through this process in necessarily time-limited courses. However, lower ethical or governance standards should not apply simply because a study is led by a student (Doyal, 2004). Doyal considered this issue in the UK and the resulting recommended safeguards for student projects were incorporated into the Warner report (Warner, 2005) (see Table 1).

The aim of this paper is to report on our 10 year experience with 90 students of community-based undergraduate research undertaken as part of an intercalated BSc in Primary Healthcare (Jones et al., 2001; 2005) and to explore the issues faced by students and faculty in undertaking this type of research.

\section{Methods and analysis}

\section{Data}

This was a qualitative study using a variety of data sources, including data from interviews and

Table 1 Summary of issues related to medical students undertaking research projects

Research is not a core skill, but improves students' critical appraisal skills, self-directed-ness, curiosity
and employability
Students become more accomplished at research and do more research
They are more likely to pursue academic careers and so build research capacity
The risks are:
Potential adverse impact on patients (direct harms, or using up their altruism)
We may put students off doing research too early in their career if they have a negative experience
Adding, possibly, stress and anxiety to student
Adding to an already overcrowded medical Undergraduate curricula

Primary Health Care Research \& Development 2008; 9: 85-95 
correspondence with students, GP tutors teaching on the course and external examiners. Other data including letters and reviews from the peer review process were collected up to 2005 to adequately reflect the development of student-directed publications. These data were then triangulated with data from our own reflections from supervising students and acting as course organizers (Jones et al., 2001; 2005). Finally, we have used original papers, and conference abstracts as outcome measures of the students' progress with disseminating their research.

\section{Interviews}

Every student enrolled from 1997 to 2002 was invited to participate. The interviews were conducted by one author (MJ) over five years. Students were interviewed after completion of their written exams and before submission of their projects, in order to maximize the response rate. Interviews were semi-structured (see interview schedule summary) and included a section focused on their experience of undertaking research.

\section{Summary of content of the student interview schedule}

Factors considered in deciding to undertake the BSc in Primary Health Care

*Thoughts about doing a research project

*Will research be something you may want to continue doing?

*Should all doctors do some research through their working lives?

Career intentions of the student postqualification

Effect of peers on career-choice

Exploration of General Practice as a positive career-choice

Other 'issues' brought to the interview by students

*Indicates part of the schedule specifically focused on student research

The interview schedule was developed from themes derived from the limited published literature and preparatory discussions, firstly with students about key issues, and secondly with course examiners and faculty members. The interviews were iterative, and flexible enough for both interviewer and interviewee to explore developing ideas and themes.

All the interviews were audio-taped and transcribed verbatim. We achieved saturation of themes; the absence of further emergent themes (Donovan and Sanders, 2005) after four cohorts of students had been interviewed.

Interviews were analysed using domain analysis and a constant comparative method (Spradley, 1979; Green, 1998). Transcripts were reviewed by two researchers (MJ and SS) for emerging themes. This was carried out independently and at different times. Any inconsistencies were discussed and agreed upon in one of four meetings, held within a month of this process. If agreement was not possible, a final arbiter was available to provide further advice (a qualitative researcher with no prior knowledge or involvement of the study). In addition, informal discussions with students at the end of term and other course feedback sessions were used to validate the themes identified.

\section{Results}

Equal proportions of the student projects have been qualitative (45/90) and quantitative projects $(45 / 90)$. Three students were unable to complete their research projects, but did submit a completed dissertation, by critiquing their failed methodology (all these candidates were awarded reasonable degrees on the basis of this critique).

\section{Project scope}

Students have undertaken a range of projects exploring a wide range of issues of interest within primary care. All students are assigned to a research project supervisor - tailored to the type of research the student is intending to do - and given guidance about the research process and its management. Students usually require very little guidance in their choice of research area, as this usually arises from the student's agenda (see section below - Development of the students' ideas). A full list of the projects is available on the website: http://www.ucl.ac.uk/pcps/education/ undergrad/bsc_pc/index.htm.

Primary Health Care Research \& Development 2008; 9: 85-95 
The projects that have been published or presented at conferences illustrate the types of research students have undertaken:

Projects about services

- NHS Direct (Ring and Jones, 2004).

- Walk-in Centres (Azad et al., 2004).

- Urgent appointments (White and Jones, 2004).

- Implementation of NICE guidelines (Mannan and Jones, 2005).

- GP participation in telemedicine (Snowden et al., 2001).

Exploring patients' and professionals' views about conditions and services

- Thallassemia (Karretti et al., 2004).

- Patient participation groups (Jayanetti and Singh, 2002).

- General Practitioner (GP) Information Technology (IT) systems (Mannan et al., 2006).

- Physical disability - blindness (Allen and Jones, 2002).

- Domestic violence among Bengali women (O’Doherty and Jones, 2005).

- Perceptions of intravenous drug-users in A\&E (Seyan and Berlin, 2006).

Treatment issues

- Drug users (Jayasooriya et al., 2001).

- Smoking cessation (Grist, 2002).

Professional issues

- Medical school entry (Greenhalgh et al., 2004; Greenhalgh et al., 2006).

- Medical student career choices (Ali and Jones, 2003).

- Medical students' health seeking behaviour (Hooper et al., 2005).

- Attitudes to drug company representatives and continuing education of students and doctors (Dogra, 2001).
Research methodologies

- Email surveys (Ali and Jones, 2002).

From the above list, it can be seen that students have chosen not just to take on 'safe' projects but have gained ethical approval to explore sensitive subject areas such as: health professionals' views about domestic violence in the Bengali women.

\section{Dissemination of the student projects}

Dissemination of the project results was not part of the course design, nor was any specific time allotted for it. However, it is a desirable outcome, both for the external prestige of the course and for the individual students. After graduation from the intercalated BSc, students return to their clinical course and MB BS final exams. Students are often unable to find the time required to turn their project into something suitable for publication, which is frustrating (but somewhat inevitable), as very few of the projects that are intrinsically interesting, ever reach the publication stage. However, for those students who do want to write up their project, converting a research project in the form of a long dissertation into something suitable to submit for publication requires considerable faculty input. Table 2 highlights the various publications, conference presentations and scholarships that have resulted from the research projects completed.

\section{Interviews}

Interview data were obtained from 24 out of 26 students, four GP tutors and two course external examiners.

Table 2 Dissemination status of student projects

\begin{tabular}{lll}
\hline Type & $\begin{array}{l}\text { No. of } \\
\text { publications }\end{array}$ & Comments \\
\hline $\begin{array}{l}\text { Research papers in peer-reviewed journal } \\
\text { Letters in peer-reviewed journal }\end{array}$ & 10 & \\
Conference presentations & 6 & $\begin{array}{l}\text { Some of these are now paper publications } \\
\text { following conference reports. } \\
\text { MRC PhD post for a BSc graduate, MRC Vacation } \\
\text { scholarship and BMJ Clegg scholarship }\end{array}$ \\
\hline
\end{tabular}

Primary Health Care Research \& Development 2008; 9: 85-95 
The key themes from the interview data are:

- Student ownership of project ideas.

- Development of the students' ideas.

- The difficulties of doing research for undergraduate researchers.

- Ethics Committee approval and the research governance process.

- Reflexivity and writing up.

- The benefits and disadvantages to students in undertaking their own research.

- Impact on students' career choices.

\section{Student ownership of project ideas}

\section{Development of the students' ideas}

Traditionally, we have offered students two routes into research projects: firstly integrating with existing departmental projects ('piggybacking') (Snowden et al., 2001; Greenhalgh et al., 2004; Seyan et al., 2004; Greenhalgh et al., 2006) and secondly, encouraging students to develop their own research question. Students find selecting a project the most daunting aspect, as they have to commit to an area, with which they have little familiarity, in the early stages of the course:

I suppose really thinking of a research question was the hardest thing to do, I found that really difficult.

(Female clinical student 1999)

... so different from the, sign up here for professor what's his name project, do some tiny slice of his research, um it, I think this how research should be you know you come up with your idea and follow it through.

(Male clinical student 2001)

Many students come to the course with relatively clear ideas about what projects they want to do.

I had ideas before, that I kind of wanted to do something along these lines.

(Female clinical student 1998)

The 'piggybacking' option is relatively unusual in our course but is more productive in terms of publications. Students largely chose to undertake their own project, refining the question and its scope during their first term with their supervisor's assistance. it becomes your baby, you know, your little project, your own little thing. And it's also quite nice in a way that I'm not tagging along with someone else. It was my own.

(Female clinical student 1998)

Students have quite a strong sense of what research is; typically this is very biomedical, quantitative research. Students are also concerned that their question has already been 'done'. The initial guidance helps them broaden their outlook on different methodologies, and to understand the iterative nature of research.

\section{The difficulties of doing research for undergraduate researchers}

Students undertake their project from initial idea to completed report in approximately nine months.

\section{Ethics Committee approval and the research governance process}

Students have to 'project-manage' their way through the full research governance process. Students and their supervisors find this a challenging process:

Ethical approval was a nightmare.

(Female clinical student 2000)

There are particular problems where ethics applications cross the interface between primary and secondary care, and the NHS and University interface.

The more recent introduction of more formalized research governance structures has added yet another layer of approval. Currently, students are typically required to have the following documents 'signed off' before research can begin:

- Research Ethics Committee (REC).

- Student Project Registration and Insurance Registration Forms (University).

- Registration with local Primary Care Trust (PCT).

- Data Protection At Registration (University).

- Honorary Contract with local PCT.

- Criminal Record Bureau (CRB) updated to within six months of start of research project.

Primary Health Care Research \& Development 2008; 9: 85-95 
Additionally, there are barriers particular to students in obtaining ethical approval, such as the need for professional and institutional indemnity, and the requirement that the applicant holds a professional appointment.

... you have to get an awful lot of important people on your side ... knowing how to explain your project

(Female clinical student 2001)

Students experience substantial delays in obtaining ethical approval, particularly where decisions are deferred. A cause of frustration has been RECs accepting applications and then several weeks later, deciding that they are outside their jurisdiction. The increasing time taken to reach decisions by Ethics Committees and research governance bodies has been particularly problematic:

... delayed ethical approval,... cut out two months out of a very tight schedule .... I couldn't do anything. So they delayed my whole project.

(Female clinical student 2000)

Anecdotally, in one case, personnel changes within the PCT meant that approval had still not occurred after more than three months, making a project unworkable:

After phoning every day (16 days) with no success ... regarding the (Ethics Committee) outcome for my project, my tutor and I decided the deadline was too tight to complete the data collection (and so the project collapsed)

(Female clinical student 2004)

Students are also asked to provide CRB checks to determine if they have criminal record:

(they) have asked me to submit (another) CRB Police check document, which is within the last 6 months ... (but) we all have police checks from starting our clinical year.

(Female clinical student 2005)

The approval process now takes up to one-third of students' available time and the burden has increased.

\section{Reflexivity and writing up the project}

The completion of the dissertation is often the most satisfying, but fraught part of the course Primary Health Care Research \& Development 2008; 9: 85-95 for students. They focus on data collection, leaving too little time for both reflection, and writing up.

... you're writing it up and you're discovering it all, that's the interesting (bit), and it just seemed the interesting bit was rushed and I didn't get as much out of it as I could have

(Female clinical student 1998)

The short time available to write projects up not only damages the quality of the dissertation, but also may lead to problems with dissemination of the results:

... if I had exams to do and do a research project in the summer term, I would be panicky. If you are going to do a research project perhaps you ought to do less exams. Give them a bit more space to think about the research project

(External Examiner 1999)

Students find it very difficult to write to a word limit, or to discard irrelevant information. However the project deadline (which is absolute), acts as a useful focus to most students, who at this stage are experienced in working to tight deadlines. As the submission date looms, students find the meeting the deadline stressful and managing this aspect can become very time consuming for both student and research supervisor. However, the competing demands of university assessment means that the time spent on the dissertation must be balanced against other learning activities and assessments that count towards the student's degree.

\section{The benefits and disadvantages for students in undertaking their own research}

Students seem to benefit considerably from undertaking their projects. They report greater self-directedness, improved knowledge of research, and increased intellectual curiosity:

I think I've got more confidence now after teaching myself. It actually takes time to sink in, which I think it has done now (Male clinical student 2001) 
To the question, 'how did you find the research project?' one student remarked:

Really tough. But really useful and I'm quite proud of ... really pleased with what I did ... and learning the research skills has been really useful, I think that's something I'll hold on to for the rest of my career

(Female clinical student 2001)

Students also gain transferable skills, such as improved critical appraisal skills:

How to look at papers, well journals, in terms of questionnaire design, validity. reliability ... I'm more confident in that area now anyway.

(Male clinical student 2001)

... having a background knowledge of how to carry out research actually helps ... with looking at things in a more evidence-based manner.

(Female clinical student 1997)

\section{Impact on students' career choices}

Students are conscious of the impact of undertaking research on their subsequent careers. A few students attempt to write up their projects immediately after the course, but we are now finding a small number of former students, from many years previously, approaching us to help them publish something, perhaps as they become aware of the potential advantage this can offer them with job applications:

For getting your house job, and for your career ... Things you do in the BSc, you can talk about as well, that makes it more interesting, for example, like your research project. Otherwise, you know, you don't have many interesting things to talk about in interview

(Female clinical student 2000)

As applications for Foundation posts become more competitive, writing up of their projects will probably become an increasing priority among students.

Some students experience a realization that they do not want to do any more research:

I have been entirely put off ever carrying out research in future

(Female clinical student 1999).
When asked, why they did not want to become a researcher, one respondent stated:

Because, I think my skills and my training could be better used actually with patients, rather than sat somewhere writing about them

(Male clinical student 1999)

And combining these two areas (patients and research):

Yeah, because I am and I have been. But, obviously you've got to work out where your priorities lie, and mine for the moment will lie in dealing with patients.

(Male clinical student 1999)

\section{Discussion}

It is undoubtedly the case that, for the majority of students, the completion of the research project for the iBSc in Primary Health Care is a positive experience. They find the research process difficult, but as we have reported elsewhere, it is often the most rewarding part of the BSc course (Jones et al., 2005). Like others (Frishman, 2001), we have identified that students seem to enjoy the journey, gain confidence in research methods, including critical appraisal and improve their selfdirectedness.

With regard to their careers, we have identified that students perceive having an intercalated BSc and research publications probably assists students when applying for posts in some disciplines of medicine, echoing observations by others (Leung, 2001; Greenhalgh and Wong, 2003). Research publications are also now part of the explicit criteria used in ranking candidates for the NHS Foundation programme. (The foundation programme committee of the Academy of Medical Royal Colleges in cooperation with Modernising Medical Careers in the Departments of Health, 2006)

There are however, some disadvantages for students, with some clearly discouraged from further involvement in research altogether. This may highlight an attitudinal problem in that some students do not appreciate that good research should lead to better clinical practice or it may be simply that some students are not suited to the demands of research.

Primary Health Care Research \& Development 2008; 9: 85-95 
Additionally, some students were clearly made quite anxious by the research governance process and the time it consumed. One student described it in an email thus:

They have sent me so many forms to fill in, they want an occupational health form, police checks, hep(atitis) B status checks, human rights form, patient ethical rights form ......... I wanna cry!!!

(Female clinical student 2005)

We have identified several logistical problems for student researchers, particularly with the time and effort required to deal with ethical, governance, data protection and other administrative hurdles. The current climate of scrutiny (without the infrastructure to respond within an adequate time) is making the position of student-led projects very precarious.

Particular problems arise where students undertake projects with human volunteers. The high level of scrutiny can result in difficulty in gaining approval. Secondly, there is a low probability that these projects will be published.

Considering first the issue of increased scrutiny, clearly, lower ethical standards as stated earlier should not apply simply because a study is led by a student (Doyal, 2004), but one could reasonably argue for proportionality in the application of those standards. The ethical and administrative standards applied appear disproportionate to the minimal risks that these student studies generate, particularly as most student projects are questionnaire or interview based. The suggestion that such studies are exploitative and exhaust participants' altruism could prevent novice researchers doing research at any level, and ultimately, this may prove more harmful than the small risks involved in student research. As all student projects are scrutinized by experienced tutors prior to Ethical Committee submission, there is an additional tier of safety in place for these studies. The present research governance structure is becoming too high a hurdle for many students to clear, and like others (Oakeshott and Yadava, 2006), we feel that this difficulty is increasing.

To deal with the second point; our outputs compare favourably with other research training programmes, such as primary care masters degrees (Calvert and Britten, 1998) and schemes for other novice researchers (Lee and Saunders,

Primary Health Care Research \& Development 2008; 9: 85-95
2004). Some of our students' projects have had real impact when published in high-impact journals (Greenhalgh et al., 2004; Seyan et al., 2004; Hooper et al., 2005) and have generated high citation indices (Snowden et al., 2001).

From a departmental perspective, as has been noted by others, considerable faculty resources are needed to support novice researchers to undertake projects and to write for publication (Stefani et al., 1997; McManus et al., 1999; Thomas and Albert, 2002). These demands must inevitably be weighed against the supervisor's competing departmental and personal priorities. The current RAE criteria (www.RAE.ac.uk) of not allowing supervisors to include their students' publications in their submission, will have an impact if maintained.

Finally, when considering the limitations of this study, we acknowledge that the authors have had a dual role in the running of the course and undertaking this evaluation. This could clearly lead to bias in our analysis. We have tried to minimize this, by checking themes identified with the students themselves, and by trying to reflect on our own preconceptions as authors. The emergent themes are a genuine distillation of student-focused factors, which appeared to characterize the interviews. There is always the danger of those most familiar with the course over-interpreting the findings; however, as has been pointed out, an explicit attempt to ensure rigour has been made by feeding back the interviews to the students informants (Mays and Pope, 2000). However, having the researchers the same as some of the course leaders means our methodology has elements of actionresearch (Meyer, 2000).

Every year we question our graduates (and ourselves) about their views on continuing with the research project. Overwhelming our exstudents respond that it is the most stressful but important and educationally useful part of the course. The governance hurdles also seem to be at least to be stabilizing (for example, with the introduction of the central COREC application process, research passports and more professionalized R\&D office services). However, it would be helpful to understand what the enablers and barriers are to the process of getting student applications over the research governance and ethical approval hurdle. While we as course organizers can make modifications to students' 
timetables to enable them to achieve deadlines for these processes, without understanding the organizations and application of ethical and governance standards within these organizations we may be wasting our time. Further research exploring these process and organizational issues is therefore needed.

In conclusion, from our study it is clear that despite the difficulties, students can successfully undertake self-directed research. Students, despite finding research difficult, find it rewarding. It places considerable burden on faculty as well as students. However, we feel that for the moment, while the endeavour is fragile, it is sustainable.

\section{References}

Ali, B. and Jones, M. 2003: Do medical students want to become GPs? British Journal of General Practice $53,241$.

Ali, B. and Jones, M. 2002: Using electronic mail as a method of surveying medical students' opinions and attitudes. Medical Education 36, 392.

Allen, R. and Jones, M. 2002: What are general practices providing in terms of aid and access for the visually impaired? British Journal of General Practice 52, $58-59$.

Azad, S., Singh, S. and Jones, M. 2004: What is the patient care pathway before and after a consultation at the NHS Soho walk in centre? Journal of Epidemiology and Community Health 58 (Suppl II), A18.

Calvert, G. and Britten, N. 1998: The UMDS MSc in general practice: attainment of intended outcomes. British Journal of General Practice 48, 1765-768.

Cursiefen, C., Beer, M. and Altunbas, A. 1995: Should all medical-students do research during their studies. Medical Education 29, 254.

Dogra, D. 2001: Attitudes of general practitioners towards pharmaceutical representatives. AUDGP London/Cambridge Regional Meeting, Madingley Hall, University of Cambridge (Conference abstract).

Donovan, J. and Sanders, C. 2005: Key issues in the analysis of qualitative data in health services research. In Bowling, A. and Ebrahim, S., editors, Handbook of health research methods, first edition. McGraw-Hill Education: Open University Press, 515-32.

Doyal, L. 2004: The ethical governance and regulation of student projects: a draft proposal. working group on Ethical Review of Student Research in the NHS. Internet Communication.

Eaton, D.G. and Thong, Y.H. 1985: The Bachelor of Medical Science research degree as a start for clinician-scientists. Medical Education 19, 445-51.
Epstein, L.M., Tamir, A., Spenser, T. and Perlman, S. 1983: The Community Project: the teaching implications of applied epidemiology. Medical Education 17, 39-44.

Frishman, W.H. 2001: Student research projects and theses: should they be a requirement for medical school graduation? Heart Disease 3, 140-44.

General Medical Council. 2002: Tomorrow's doctors (recommendations on undergraduate medical education). London: General Medical Council.

Gonzales, A.O., Westfall, J. and Barley, G.E. 1998: Promoting medical student involvement in primary care research. Family Medicine 30, 113-16.

Green, J. 1998: Grounded theory and the constant comparative method. British Medical Journal 136, 1064-65.

Greenhalgh, T., Seyan, K. and Boynton, P. 2004: Not a university type: focus group study of social class, ethnic, and sex differences in school pupils' perceptions about medical school. British Medical Journal 328, 1541.

Greenhalgh, T. and Wong, G. 2003: Doing an intercalated BSc can make you a better doctor. Medical Education 37, 760-61.

Greenhalgh, T., Russell, J., Boynton, P., Lefford, F., Chopra, N. and Dunkley, L. 2006: "We were treated like adults" - development of a pre-medicine summer school for 16 year olds from deprived socioeconomic backgrounds: action research study. British Medical Journal 332, 762-67.

Grist M. 2002: GPs' attitudes to smoking cessation provision. AUDGP London Regional Conference, Madingley Hall, University of Cambridge (Conference abstract).

Griswold, K., Silverstein, D., Lenkei, E. and Fiedler, R. 1991: Research skills for medical students: a summer assistantship in family medicine. Family Medicine 23, 306-07.

Hebert, R.S., Levine, R.B., Smith, C.G. and Wright, S.M. 2003: A systematic review of resident research curricula. Academic Medicine 78, 61-68.

Heylings, D.J.A. and Tariq, V.N. 2001: Reflection and feedback on learning: a strategy for undergraduate research project work. Assessment \& Evaluation in Higher Education 26, 153-64.

Hooper, C., Meakin, R. and Jones, M. 2005: Where students go when they are ill: how medical students access health care. Medical Education 39, 588-93.

Jacobs, C.D. and Cross, P.C. 1995: The value of medical student research: the experience at Stanford University School of Medicine. Medical Education 29, $342-46$.

Jayanetti, N. and Singh, S. 2002: The dynamics of a patient participation group. The International Social Anthropology Conference, Brunel University (Conference abstract).

Jayasooriya, S. McCallum, A. and Kemp, K. 2001: Primary care services received by the children of people with substance misuse problems. Faculty of Public Health

Primary Health Care Research \& Development 2008; 9: 85-95 
Medicine of the Royal College of Physicians, 2001 Annual Scientific Meeting (Conference abstract).

Joffe, M. and Farrant, W. 1989: Medical student projects in practical health promotion. Community Medicine 11, 35-40.

Jones, M., Lloyd, M. and Meakin, R. 2001: Intercalated BSc in Primary Health Care - an outline of a new course. Medical Teacher 23, 95-97.

Jones, M., Singh, S. and Lloyd, M. 2005: "It isn't just consultants that need a BSc": student experiences of an Intercalated BSc. in Primary Health Care. Medical Teacher 27, 164-68.

Jones, K.V. and Hsu-Hage, B.H. 1999: Health promotion projects: skill and attitude learning for medical students. Medical Education 33, 585-91.

Joubert, G. 2006: Research by pre-clinical undergraduate medical students. Medical Education 40, 470-71.

Karretti, M., Yardumian, A., Karretti, D. and Modell, B. 2004: Informing carriers of beta thallassemia: giving the good news. Genetic Testing 8, 109-13.

Kemph, J.P., Sodeman, W., Claybrook, J.R. and Rand, C. 1991: A follow-up of a program to foster medical students' interest in research and academic careers. Academic Medicine 66, 122.

Lambert, T.W., Goldacre, M.J., Davidson, J.M. and Parkhouse, J. 2001: Graduate status and age at entry to medical school as predictors of doctors' choice of long-term career. Medical Education 35, 450-54.

Lee, M. and Saunders, K. 2004: Oak trees from acorns? An evaluation of local bursaries in primary care. Primary Health Care Research and Development 5, 93-95.

Leung, W. 2001: Is studying for an intercalated degree a wise career move? Student BMJ 9, 418-19.

Mannan, R., Jones, M. and Murphy, J. 2006: Is primary care ready to embrace e-health? A qualitative study of staff in a London Primary Care Trust. Informatics in Primary Care 14, 121-31.

Mannan, R. and Jones, M. 2005: What's the evidence that NICE guidance has been implemented? Maybe NICE needs to do more to ensure implementation of guidelines. British Medical Journal 330, 1085.

Mant, D. 1997: Research and development in primary care: National Working Group report (Mant report). London: NHS Executive Department of Heath.

Mays, N. and Pope, C. 2000: Qualitative research in health care: assessing quality in qualitative research. British Medical Journal 320, 50-52.

McManus, I.C., Richards, P. and Winder, B.C. 1999: Intercalated degrees, learning styles, and career preferences: prospective longitudinal study of UK medical students. British Medical Journal 319, 542-46.

Meyer, J. 2000: Qualitative research in health care: using qualitative methods in health related action research. British Medical Journal 320, 178-81.

Morrison, J. 2004: Academic medicine and intercalated BScs. Medical Education 38, 1128-129.

Primary Health Care Research \& Development 2008; 9: 85-95
Murdoch-Eaton, D. and Jolly, B. 2000: Undergraduate projects - do they have to be within the conventional medical environment? Medical Education 34, 95-100.

O'Doherty, C. and Jones, M. 2005: Domestic violence in the Bengali community. British Journal of General Practice 55, 715-16.

Oakeshott, P. and Yadava, R. 2006: Research governance: major barrier to student research. British Journal of General Practice 56, 139-40.

Reuben, D.B. and Smith, S.R. 1987: Community health projects as part of a core clinical clerkship: teaching research skills in a community setting. Journal of Community Health 12, 257-64.

Ring, F. and Jones, M. 2004: NHS Direct usage in a GP population of children under 5 years: is NHS Direct being used by people with the greatest health need? British Journal of General Practice 54, 211-13.

Segal, S., Lloyd, T., Houts, P.S., Stillman, P.L., Jungas, R.L. and Greer, III R.B. 1990: The association between students' research involvement in medical school and their postgraduate medical activities. Academic Medicine $65,530-33$.

Seyan, J. and Berlin, A. 2006: A qualitative study to explore intravenous drug users experience of accident and emergency and their experience of Primary Health Care. SAPC London Regional Conference, Madingley Hall, University of Cambridge (Conference abstract).

Seyan, K., Greenhalgh, T. and Dorling, D. 2004: The standardised admission ratio for measuring widening participation in medical schools: analysis of UK medical school admissions by ethnicity, socioeconomic status, and sex. British Medical Journal 328, 1545-546.

Shapiro, J., Coggan, P., Rubel, A., Morohasi, D., Fitzpatrick, C. and Danque, F. 1994: The process of faculty-mentored student research in family medicine: motives and lessons. Family Medicine 26, 283-89.

Smith, R. 1986: A senseless sacrifice: the fate of intercalated degrees. British Medical Journal (Clinical Research Ed.) 292, 1619-620.

Snowden, S., Harrison, R. and Wallace, P. 2001: General practitioner participants in a telemedicine trial: comparisons with their peers. Journal of Telemedicine and Telecare 7, 32-37.

Spradley, J.P. 1979: The Ethnographic interview. Thomson Learning.

Stefani, L.A., Tariq, V.N., Heylings, D.J.A. and Butcher, A.C. 1997: A comparison of tutor and student conceptions of undergraduate research project work. Assessment \& Evaluation in Higher Education 22, 271-88.

The Foundation Programme Committee. 2005: The Foundation Programme Committee of the Academy of Medical Royal Colleges in cooperation with Modernising Medical Careers in the Departments of Health. Curriculum for the foundation years in 
postgraduate education and training. Departments of Health.

Thomas, P. and Albert, T. 2002: Getting primary care research published: the experience of the WeLReN writers' support group. Primary Health Care Research and Development 3, 210-11.

Warner. 2005: Report of the Ad Hoc Advisory Group on the Operation of NHS Research Ethics Committees, Department of Health.
White, S. and Jones, M. 2004: Impact of advanced access. British Journal of General Practice 54, 622.

Wyllie, A.H. and Currie, A.R. 1986: The Edinburgh intercalated honours BSc in pathology: evaluation of selection methods, undergraduate performance, and postgraduate career. British Medical Journal (Clinical Research Ed.) 292, 1646-648.

Zier, K. and Stagnaro-Green, A. 2001: A multifaceted program to encourage medical students' research. Academic Medicine 76, 743-47. 